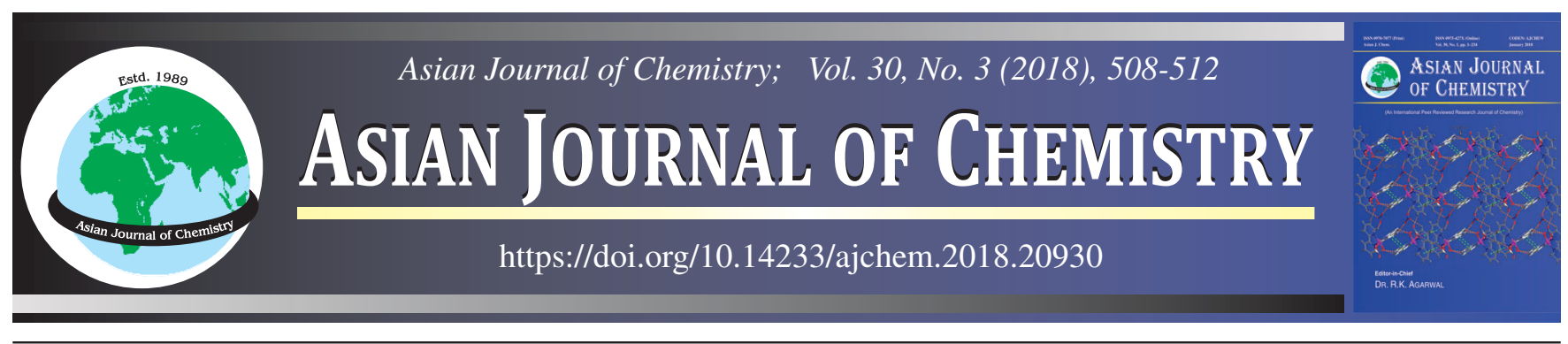

\title{
Comparative Analysis of Phytochemical Profile and Antioxidant Activity of Coriander (Coriandrum sativum L.)
}

\author{
Satya Shree Jangra, V. K. Madan*, Isha Singh and Dusyant
}

Medicinal \& Aromatic Plants Section, Old IATTE Building, Chaudhary Charan Singh Haryana Agricultural University, Hisar-125 004, India

*Corresponding author: E-mail: vikku60@gmail.com

Received: 18 July 2017; Accepted: 18 September 2017;

Published online: 31 January 2018;

AJC-18733

In the present investigation, two varieties viz. DH-5 and DH-36 of coriander (Coriandrum sativum L.) were assayed for their phytochemical profile and screened for their DPPH free radical scavenging activity and antioxidant activity. Phytochemicals from coriander leaves were extracted using water, ethanol and acetone. The results revealed that among the two varieties; DH-5 had higher total phenolics, flavonoids, chlorophyll-a and chlorophyll-b contents, moreover DH-5 also exhibited higher DPPH free radical scavenging activity and antioxidant activity by $\beta$-carotene bleaching method in comparison to DH-36. DPPH free radical scavenging activity of extracts increased with increase of concentration levels. Amongst the different extracts, acetone extract of both varieties of coriander contained highest flavonoids content and also exhibited highest antioxidant activity whereas total phenolics were found to be highest in water extract of both varieties.

| Keywords: Coriandrum sativum, Phenolics, Flavonoids. Chlorophyll-a, Chlorophyll-b, Antioxidant activity.

ᄂ - - - - - - - - - - - - - - - -

\section{INTRODUCTION}

Dietary phytochemicals are considered as an effective tool to cure various human physiological disorders. Several epidemiological studies have indicated that high intake of natural products is associated with reduced risk of a number of chronic diseases such as artherosclerosis and cancer [1]. During recent years consumers have been more concerned about the addition of synthetic additives to food and the two most commonly used antioxidants, butylated hydroxyanisole (BHA) and butylated hydroxytoluene (BHT), have shown DNA damage induction [2]. Therefore, an interest is growing for the search of natural antioxidants for the public perception that natural and dietary antioxidants are safer than synthetic analogues $[3,4]$. From the safety point of view, one of the important sources for the search of natural antioxidants are herbs and spices. Among them, coriander has much importance due to its versatile use as a spice as well as an herb.

Coriandrum sativum L., commonly known as coriander, is an aromatic annual herb belonging to family Umbelliferae. It is extensively cultivated in India, Asia, Middle East, Central Europe and Russia for its seeds and foliage. It is used all over the world as culinary spice and flavouring agent because of its various medicinal/aromatic applications. The major phytochemicals in the leaves and seeds of coriander are tocopherols, carotenoids, chlorophylls, sugars, ascorbic acid, phenolics, flavonoids, tannins and anthocyanins [5]. Coriander has tradi- tionally been referred to as antidiabetic [6], antiinflammatory and cholesterol lowering agent $[7,8]$.

Antioxidant compounds, present in plants, are of diverse structure and their activity in different model systems and extractability is strongly dependent on their chemical structure, so different extraction media i.e. solvent systems, may provide varying yields of extracts with selective recovery of antioxidants; depending on the structure of antioxidant compounds present in the plants [9]. Most of the research works in coriander have been focused on its seeds $[10,11]$ and little attention has been paid to the chemical constituents in leaves [12], although foliage is popular for their versatile use in various types of foods. Therefore, the present study was carried out to investigate the phytochemical profile of leaves of two varieties viz. DH-5 and DH36 of coriander and to evaluate their antioxidant potential.

\section{EXPERIMENTAL}

Plant material and extraction: Fresh coriander leaves were procured from the Research Farm of Department of Vegetable Science of CCS Haryana Agricultural University, Hisar, India. Two varieties of coriander viz., DH-5 and DH-36 were taken for investigation. Water, ethanol and acetone extracts were prepared with ten gram coriander leaves following method described in earlier publication [13]. Water, ethanol and acetone extracts of coriander leaves were then used for determination of total phenolics content, flavonoids content and for evaluation of antioxidant potential. 
Estimation of moisture content: Fresh coriander leaves $(10 \mathrm{~g})$ homogenized pulp was taken in three replications and dried completely at $100-102^{\circ} \mathrm{C}$. Weights of dry samples were noted till constant weights were obtained. The percentage of moisture content was calculated using eqn. 1 :

Moisture content $(\%)=\frac{\text { Wt. of fresh pulp }- \text { Wt of dry pulp }}{\text { Wt. of fresh pulp }} \times 100$

The data of moisture content was used to calculate the amount of various phyto-chemicals on dry weight basis (dwb).

Estimation of total phenolics content: Total phenolics content of coriander leaves extracts was estimated using FolinCiocalteu method $[13,14]$.

Estimation of flavonoids content: Flavonoids content of coriander leaves extracts was estimated by aluminum chloride colorimetric assay $[13,15]$.

Estimation of chlorophyll-a and chlorophyll-b content: The photosynthetic pigments i.e. chlorophyll-a and chlorophyll-b in coriander leaves was determined as per the method of Hiscox and Israelstam [16]. Finely chopped leaves (100 mg) excluding veins were washed and placed in tubes containing $5 \mathrm{~mL}$ of solvent. Various solvents taken for study were: DMSO, DMSO :acetone $(1: 1, v / v)$, DMSO:ethanol $(1: 1, \mathrm{v} / \mathrm{v})$, DMSO:water $(1: 1, \mathrm{v} / \mathrm{v})$, acetone, ethanol and water. The tubes were incubated at $65{ }^{\circ} \mathrm{C}$ for $75 \mathrm{~min}$ so that the chlorophyll gets extracted into the solvents from finely chopped leaves. The extracted liquid was transferred to $10 \mathrm{~mL}$ graduated cylinders and volume was made up to the mark with respective solvents. The absorbance was measured at 645 and $663 \mathrm{~nm}$ for chlorophyll-a and chlorophyll-b, respectively using respective solvent as blank in UV-visible spectrophotometer. The concentration of chlorophyll-a and chlorophyll-b was calculated on fresh weight basis according to the eqn. 2 :

Chlorophyll-a $(\mathrm{mg} / \mathrm{g})=\left[12.7\left(\mathrm{~A}_{663}\right)-2.69\left(\mathrm{~A}_{645}\right)\right] \times \frac{\mathrm{V}}{1000 \times \mathrm{W}}$

Chlorophyll-b $(\mathrm{mg} / \mathrm{g})=\left[22.9\left(\mathrm{~A}_{645}\right)-4.68\left(\mathrm{~A}_{663}\right)\right] \times \frac{\mathrm{V}}{1000 \times \mathrm{W}}$

where, $\mathrm{A}=$ absorbance at specific wavelengths; $\mathrm{V}=$ final volume of extract $(\mathrm{mL}) ; \mathrm{W}=$ fresh weight $(\mathrm{g})$ of tissue extracted.

DPPH free radical scavenging activity: The antioxidant activity of the extracts was evaluated by 2,2'-diphenyl-1-picrylhydrazyl (DPPH) free radical scavenging method [17]. From acetone, ethanol and water extracts, stock solution $(5.0 \mathrm{mg} / \mathrm{mL})$ was prepared as described in earlier publication [13]. From stock solution, different concentrations $(0.25-5.0 \mathrm{mg} / \mathrm{mL})$ were made by appropriate dilutions with respective solvents (i.e. methanol for acetone and ethanol extracts and with methanol :water for water extracts). 2,2'-Diphenyl-1-picrylhydrazyl (DPPH) free radical scavenging activity of various extracts was evaluated [13]. The percentage of DPPH scavenged (\% DPPH ${ }_{\text {sc }}^{*}$ ) was calculated using eqn. 3 :

$$
\operatorname{DPPH}_{\text {sc }}^{*}(\%)=\frac{\mathrm{A}_{\text {control }}-\mathrm{A}_{\text {sample }}}{\mathrm{A}_{\text {control }}} \times 100
$$

where, $\mathrm{A}=$ control is the absorbance of control and $\mathrm{A}=$ sample is the absorbance of sample.

Antioxidant activity: Antioxidant activity was measured by $\beta$-carotene bleaching method $[13,18]$. The antioxidant activity of different solvent extracts of coriander leaves was calculated using eqn. 4 :

$\mathrm{A}_{\mathrm{A}}(\%)=\frac{\left[\left(\mathrm{A}_{\mathrm{o}}\right)_{\text {control }}-\left(\mathrm{A}_{\mathrm{t}}\right)_{\text {control }}\right]-\left[\left(\mathrm{A}_{\mathrm{o}}\right)_{\text {sample }}-\left(\mathrm{A}_{\mathrm{t}}\right)_{\text {sample }}\right]}{\left[\left(\mathrm{A}_{\mathrm{o}}\right)_{\text {control }}-\left(\mathrm{A}_{\mathrm{t}}\right)_{\text {control }}\right]} \times 100$

where, $\left(\mathrm{A}_{0}\right)_{\text {control }}$ and $\left(\mathrm{A}_{\mathrm{o}}\right)_{\text {sample }}$ are the absorbance values measured at zero time of incubation for the control and sample, respectively and $\left(\mathrm{A}_{\mathrm{t}}\right)_{\text {control }}$ and $\left(\mathrm{A}_{\mathrm{t}}\right)_{\text {sample }}$ are the corresponding values at the end of the reaction time.

\section{RESULTS AND DISCUSSION}

Moisture content and extract yield: The moisture content of coriander varieties DH-5 and DH-36 was found to be 87.81 and $87.67 \%$, respectively. Extract yield of coriander extracts in the tested solvents is given in Table-1. Ethanol extract of coriander variety DH-5 showed highest extract yield $(\mathrm{g} / 100 \mathrm{~g})$ i.e. 3.35 followed by acetone (2.45) and water (2.43) extracts. Similarly, ethanol extract of coriander variety DH-36 also showed highest extract yield $(\mathrm{g} / 100 \mathrm{~g})$ i.e. 2.59 followed by acetone (2.22) and water (1.99) extracts. The present finding is in agreement with the previous study [19], which reported that ethanolic extracts of shrubs (P. tridentatum, C. scoparius and Erica spp.) also showed higher extract yields than the aqueous extracts.

Total phenolics content: Total phenolics content in different solvent extracts (acetone, ethanol and water) of the two varieties of coriander is shown in Table-1. On fresh weight basis, water extract of coriander variety DH-5 contained the highest total phenolics content (mg GAE/g fwb) i.e. 1.09 followed by ethanol (0.89) and acetone (0.75) extracts. Similarly, water extract of coriander variety DH-36 contained the highest total phenolics content (mg GAE/g fwb) i.e. 0.86 followed by ethanol (0.76) and acetone (0.62) extracts. Similar trend was observed on dry weight basis for both varieties (Table-1). Some other research workers [20] have also reported similar findings. The total phenolics content has been reported to be $1.22 \mathrm{mg} / \mathrm{g}$ fwb and $7.01 \mathrm{mg} / \mathrm{g}$ $\mathrm{dwb}$ in coriander. The results are in agreement to the previous study [21] where water was most effective in extracting phenolic

TABLE-1

EXTRACT YIELD, TOTAL PHENOLICS AND FLAVONOIDS CONTENTS IN CORIANDER VARIETIES EXTRACTED WITH DIFFERENT SOLVENTS

\begin{tabular}{|c|c|c|c|c|c|c|c|c|c|c|}
\hline \multirow{3}{*}{ Solvent } & \multicolumn{5}{|c|}{ Variety: DH-5 } & \multicolumn{5}{|c|}{ Variety: DH-36 } \\
\hline & \multirow{2}{*}{$\begin{array}{c}\text { Extract } \\
\text { yield } \\
(\mathrm{g} / 100 \mathrm{~g})\end{array}$} & \multicolumn{2}{|c|}{$\begin{array}{c}\text { Total phenolics } \\
\text { content (mg GAE/g) }\end{array}$} & \multicolumn{2}{|c|}{$\begin{array}{c}\text { Flavonoids content } \\
(\mathrm{mg} \mathrm{CE} / \mathrm{g})\end{array}$} & \multirow{2}{*}{$\begin{array}{c}\text { Extract } \\
\text { yield } \\
(\mathrm{g} / 100 \mathrm{~g})\end{array}$} & \multicolumn{2}{|c|}{$\begin{array}{c}\text { Total phenolics } \\
\text { content (mg GAE/g) }\end{array}$} & \multicolumn{2}{|c|}{$\begin{array}{l}\text { Flavonoids content } \\
\text { (mg CE/g) }\end{array}$} \\
\hline & & fwb & $\mathrm{dwb}$ & fwb & $\mathrm{dwb}$ & & Fwb & $\mathrm{dwb}$ & fwb & $\mathrm{dwb}$ \\
\hline Acetone & $2.45 \pm 0.03$ & $0.75 \pm 0.01$ & $6.18 \pm 0.10$ & $1.27 \pm 0.02$ & $10.44 \pm 0.14$ & $2.22 \pm 0.02$ & $0.62 \pm 0.01$ & $5.06 \pm 0.12$ & $1.17 \pm 0.01$ & $9.49 \pm 0.09$ \\
\hline Ethanol & $3.35 \pm 0.03$ & $0.89 \pm 0.01$ & $7.27 \pm 0.12$ & $1.15 \pm 0.01$ & $9.41 \pm 0.12$ & $2.59 \pm 0.03$ & $0.76 \pm 0.02$ & $6.14 \pm 0.15$ & $1.03 \pm 0.02$ & $8.35 \pm 0.17$ \\
\hline Water & $2.43 \pm 0.02$ & $1.09 \pm 0.01$ & $8.97 \pm 0.10$ & $0.47 \pm 0.02$ & $3.88 \pm 0.14$ & $1.99 \pm 0.03$ & $0.86 \pm 0.01$ & $6.97 \pm 0.10$ & $0.36 \pm 0.01$ & $2.95 \pm 0.10$ \\
\hline
\end{tabular}


compounds from Rang Chuet followed by ethanol and acetone. Similarly, the phenolic content of mushroom samples extracted with water and hot water were much higher than those extracted with acetone and ethanol [22].

Flavonoids content: Flavonoids content in different solvent extracts (acetone, ethanol and water) of the two varieties of coriander is shown in Table-1. On fresh weight basis, acetone extract of coriander variety DH-5 contained the highest flavonoids content (mg CE/g fwb) i.e. 1.27 followed by ethanol (1.15) and water (0.47) extracts. Similarly, acetone extract of coriander variety DH-36 contained the highest flavonoids content (mg $\mathrm{CE} / \mathrm{g}$ fwb) i.e. 1.17 followed by ethanol (1.03) and water (0.36) extracts. Similar trend was observed on dry weight basis for both varieties (Table-1). Flavonoids content in coriander leaf has been reported to be $0.93 \mathrm{mg} / \mathrm{g}$ on fresh weight basis by other research workers [23]. This finding is in agreement with the previous observation [24] that acetone extract of C. papaya seeds showed maximum flavonoids content followed by ethanol and water extracts. Similarly, acetone was the best solvent for extracting flavonoids from bitter melon followed by ethanol and water [25].

Chlorophyll-a and chlorophyll-b contents: Chlorophyll-a and chlorophyll-b contents of coriander varieties viz. DH-5 and DH-36 in seven solvents are given in Table-2. Chlorophylla content (mg/g fwb) in coriander variety DH-5 was highest in DMSO:acetone extract (1.67) followed by ethanol (1.58), DMSO:ethanol (1.54), DMSO (1.48), DMSO:water (0.31), acetone $(0.21)$ and water $(0.03)$ extracts on fresh weight basis (Table-2). Similarly, in coriander variety DH-36, chlorophylla content (mg/g fwb) was highest in DMSO:acetone extract (1.32) followed by ethanol (1.28), DMSO:ethanol (1.25), DMSO (1.20), DMSO:water (0.28), acetone (0.17) and water $(0.02)$ extracts on fresh weight basis. Similar trend was observed on dry weight basis for both varieties (Table-2).

Chlorophyll-b content $(\mathrm{mg} / \mathrm{g}$ fwb) in coriander variety DH-5 was found to be highest in DMSO:acetone extract (0.54) followed by ethanol (0.48), DMSO:ethanol (0.45), DMSO (0.44), DMSO:water (0.15), acetone (0.11) and water (0.03) extracts on fresh weight basis (Table-2). Similarly, in coriander variety DH-36, chlorophyll-b content (mg/g fwb) was highest in DMSO: acetone extract (0.42) followed by ethanol (0.36), DMSO: ethanol (0.35), DMSO (0.31), DMSO:water (0.11), acetone (0.09) and water (0.02) extracts on fresh weight basis (Table-2). Similar trend was also observed on dry weight basis for both varieties (Table-2).

In present studies, chlorophyll-a and chlorophyll-b were higher or at par in DMSO:acetone, ethanol and DMSO:ethanol solvent systems in comparison to DMSO solvent being used in the standard method [16], which shows that DMSO:acetone, ethanol and DMSO:ethanol solvents can also be used for estimation of chlorophyll-a and chlorophyll-b. The chlorophylla, chlorophyll-b and total chlorophyll contents in Coriandrum sativum $\mathrm{L}$. leaves have been reported to be 1.95, 0.66 and 2.60 $\mathrm{mg} / \mathrm{g}$ fwb in acetone [26]. The total chlorophyll (Chl. a + Chl. b) content in coriander leaves extracted with $95 \%$ ethanol at $80{ }^{\circ} \mathrm{C}$ was $2.28 \mathrm{mg} / \mathrm{g}$ fwb [27].

DPPH free radical scavenging activity: DPPH free radical scavenging activity was measured by the decrease in absorbance as the DPPH radical received an electron or hydrogen radical from an antioxidant compound to become a stable diamagnetic molecule [28]. DPPH free radical scavenging activity (\%) of the acetone, ethanol and water extracts of coriander varied widely and it increased with increase of concentration levels. DPPH free radical scavenging activity $(\%)$ of coriander variety DH-5 ranged from 8.3 to $81.7 \%$ (acetone extract), from 6.5 to $75.4 \%$ (ethanol extract) and from 2.3 to $57.0 \%$ (water extract) at different concentration levels ranging from 0.25 to $5.0 \mathrm{mg} / \mathrm{mL}$ (Table-3). The $\mathrm{IC}_{50}$ value of acetone extract was lowest i.e. 1.6 $\mathrm{mg} / \mathrm{mL}$ followed by $2.3 \mathrm{mg} / \mathrm{mL}$ of ethanol extract and $4.0 \mathrm{mg} / \mathrm{mL}$ of water extract thereby showing that acetone extract has highest activity followed by ethanol and water extracts. Coriander variety DH-36 data showed that amongst solvents, DPPH free

TABLE-2

CHLOROPHYLL-a AND CHLOROPHYLL-b CONTENTS IN CORIANDER VARIETIES EXTRACTED WITH DIFFERENT SOLVENTS

\begin{tabular}{|c|c|c|c|c|c|c|c|c|}
\hline \multirow{3}{*}{ Solvent } & \multicolumn{4}{|c|}{ Variety: DH-5 } & \multicolumn{4}{|c|}{ Variety: DH-36 } \\
\hline & \multicolumn{2}{|c|}{ Chlorophyll-a (mg/g) } & \multicolumn{2}{|c|}{ Chlorophyll-b (mg/g) } & \multicolumn{2}{|c|}{ Chlorophyll-a (mg/g) } & \multicolumn{2}{|c|}{ Chlorophyll-b (mg/g) } \\
\hline & fwb & $\mathrm{dwb}$ & fwb & dwb & fwb & dwb & fwb & dwb \\
\hline DMSO & $1.48 \pm 0.03$ & $12.14 \pm 0.2$ & $44 \pm 0$ & $88+0$ & $1.20 \pm 0.02$ & $9.73 \pm 0$ & $0.31 \pm 0.01$ & $2.51 \pm 0.05$ \\
\hline DMSO:Aceto & $1.67 \pm 0.02$ & $13.73 \pm 0.15$ & $0.54 \pm 0.02$ & $3 \pm 0.17$ & $1.32 \pm 0.01$ & $10.73 \pm 0.12$ & $0.42 \pm 0.01$ & 0.10 \\
\hline DMSO:Ethanol (1:1) & $1.54 \pm 0.01$ & $12.66 \pm 0.12$ & $0.45 \pm 0.01$ & $3.72 \pm 0.05$ & $1.25 \pm 0.02$ & $10.14 \pm 0.14$ & $0.35 \pm 0.03$ & $2.81 \pm 0.24$ \\
\hline DMSO:Water $(1: 1)$ & $0.31 \pm 0.01$ & $2.54 \pm 0.08$ & $0.15 \pm 0.01$ & $1.26 \pm 0.12$ & $0.28 \pm 0.01$ & $2.24 \pm 0.07$ & $0.11 \pm 0.01$ & $0.92 \pm 0.07$ \\
\hline Acetone & $0.21 \pm 0.01$ & $1.72 \pm 0.05$ & $0.11 \pm 0.01$ & $0.93 \pm 0.05$ & $0.17 \pm 0.00$ & $1.41 \pm 0.03$ & $0.09 \pm 0.00$ & $0.70 \pm 0.03$ \\
\hline Ethanol & $1.58 \pm 0.02$ & $12.93 \pm 0.14$ & $0.48 \pm 0.01$ & $3.94 \pm 0.05$ & $1.28 \pm 0.02$ & $10.41 \pm 0.15$ & $0.36 \pm 0.01$ & $2.95 \pm 0.03$ \\
\hline Water & $0.03 \pm 0.00$ & $0.22 \pm 0.03$ & $0.03 \pm 0.00$ & $0.25 \pm 0.00$ & $0.02 \pm 0.00$ & $0.16 \pm 0.00$ & $0.02 \pm 0.00$ & $0.19 \pm 0.03$ \\
\hline
\end{tabular}

TABLE-3

DPPH FREE RADICAL SCAVENGING ACTIVITY (\%) OF DIFFERENT EXTRACTS OF CORIANDER VARIETIES DH-5 AND DH-36

\begin{tabular}{|c|c|c|c|c|c|c|c|}
\hline \multirow{3}{*}{ Variety } & \multirow{3}{*}{ Extracts } & \multicolumn{5}{|c|}{ DPPH free radical scavenging activity (\%) } & \multirow{3}{*}{$\mathrm{IC}_{50}(\mathrm{mg} / \mathrm{mL})$} \\
\hline & & \multicolumn{5}{|c|}{ Concentration $(\mathrm{mg} / \mathrm{mL})$} & \\
\hline & & 5.0 & 2.5 & 1.0 & 0.5 & 0.25 & \\
\hline \multirow{3}{*}{ DH-5 } & Acetone & $81.7 \pm 0.38$ & $68.9 \pm 0.36$ & $33.2 \pm 0.32$ & $17.1 \pm 0.26$ & $8.3 \pm 0.15$ & $1.6 \pm 0.19$ \\
\hline & Ethanol & $75.4 \pm 0.32$ & $53.0 \pm 0.42$ & $24.4 \pm 0.32$ & $11.2 \pm 0.38$ & $6.5 \pm 0.31$ & $2.3 \pm 0.15$ \\
\hline & Water & $57.0 \pm 0.49$ & $35.7 \pm 0.38$ & $13.5 \pm 0.31$ & $7.5 \pm 0.38$ & $2.3 \pm 0.32$ & $4.0 \pm 0.32$ \\
\hline \multirow{3}{*}{ DH-36 } & Acetone & $78.6 \pm 0.36$ & $65.8 \pm 0.44$ & $30.4 \pm 0.26$ & $15.5 \pm 0.36$ & $6.9 \pm 0.21$ & $1.7 \pm 0.21$ \\
\hline & Ethanol & $74.0 \pm 0.42$ & $50.3 \pm 0.44$ & $20.2 \pm 0.38$ & $10.9 \pm 0.32$ & $5.4 \pm 0.21$ & $2.5 \pm 0.26$ \\
\hline & Water & $54.2 \pm 0.38$ & $31.3 \pm 0.36$ & $11.9 \pm 0.32$ & $5.2 \pm 0.26$ & $1.6 \pm 0.15$ & $4.4 \pm 0.23$ \\
\hline
\end{tabular}


radical scavenging activity $(\%)$ ranged from 6.9 to $78.6 \%$ (acetone extract), from 5.4 to $74.0 \%$ (ethanol extract) and from 1.6 to $54.2 \%$ (water extract) at different concentration levels ranging from 0.25 to $5.0 \mathrm{mg} / \mathrm{mL}$ (Table-3). The $\mathrm{IC}_{50}$ value of acetone extract was lowest i.e. $1.7 \mathrm{mg} / \mathrm{mL}$ followed by $2.5 \mathrm{mg} / \mathrm{mL}$ of ethanol extract and $4.4 \mathrm{mg} / \mathrm{mL}$ of water extract thereby showing that acetone extract has highest activity followed by ethanol and water extracts. The quadratic regression equations for calculating $\mathrm{IC}_{50}$ values are shown in Figs. 1 and 2. The present findings are in agreement with the studies on D. dichotoma and $T$. ornata where the acetone extracts had higher DPPH free radical scavenging activity as compared to their ethanol extracts [29]. In other studies [30], ethanol and methanol extracts of black and red currant had higher antioxidant activity in comparison to water extract whereas highest DPPH radical scavenging effect was observed in acetone extract of Onosma dichroanthum Boiss. root with $\mathrm{EC}_{50} 4.06 \mathrm{mg}$ [31].

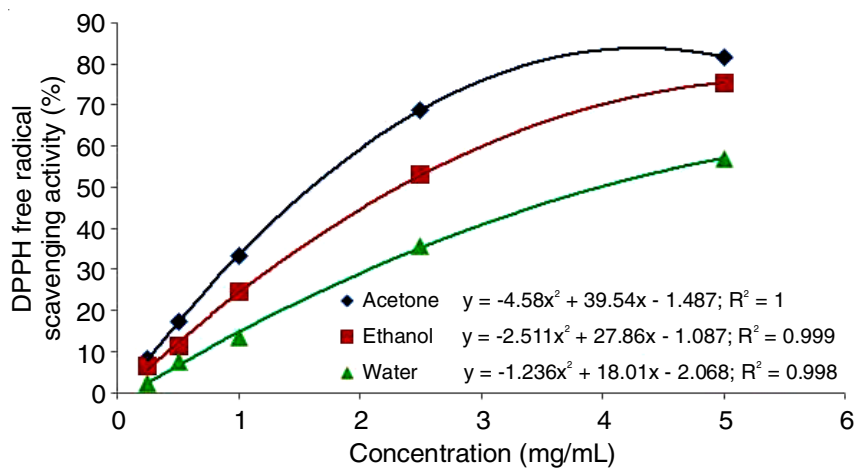

Fig. 1. Quadratic regression equations for $\mathrm{IC}_{50}$ values of different extracts of coriander (DH-5)

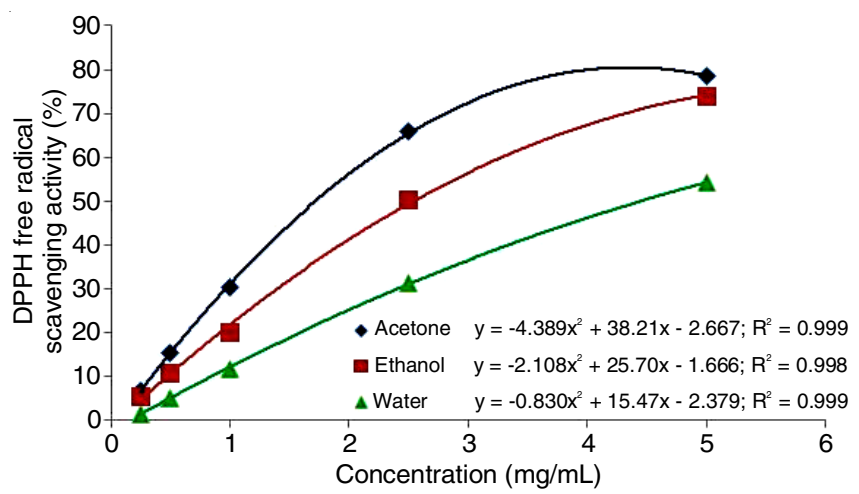

Fig. 2. Quadratic regression equations for $\mathrm{IC}_{50}$ values of different extracts of coriander (DH-36)

Antioxidant activity: Antioxidant activity of water, ethanol and acetone extracts of leaves of both coriander varieties was evaluated by $\beta$-carotene bleaching method which measures the ability of an antioxidant to inhibit lipid peroxidation. Acetone extract of coriander variety DH-5 showed highest antioxidant activity (72.6\%) followed by ethanol extract (65.9\%) and water extract (50.6\%) at $5 \mathrm{mg} / \mathrm{mL}$ concentration level. Similarly, acetone extract of coriander variety DH-36 also showed highest antioxidant activity $(70.7 \%)$ followed by ethanol extract (63.1 $\%$ ) and water extract (48.2\%) at $5 \mathrm{mg} / \mathrm{mL}$ concentration level. These results are supported by the previous study that evaluated the antioxidant activity of extracts from 36 vegetables by using $\beta$-carotene bleaching method and reported that the ethanol extracts of all vegetables showed higher antioxidant activity when compared with their water extracts [32]. The antioxidant activity of seaweeds (Wakame and Hijiki) by $\beta$-carotene bleaching method was found to be higher in ethanolic extracts in comparison to water extracts and the difference might probably be due to the different characteristics of the antioxidant components extracted from the seaweeds matrix [33].

\section{Conclusion}

In present study, the extracting solvents affected total phenolics, flavonoids, chlorophyll-a and chlorophyll-b contents as well as their DPPH free radical scavenging and antioxidant activity. Among the two varieties of coriander, variety DH-5 contained higher total phenolics, flavonoids, chlorophyll-a and chlorophyll-b contents and also exhibited higher antioxidant activity in comparison to variety DH-36. Hence, coriander can be considered as a useful source of natural antioxidants for human health.

\section{REFERENCES}

1. M. Ajmal, M.S. Butt, M.K. Sharif, M. Nasir and M.T. Nadeem, Int. J. Food Prop., 9, 623 (2006); https://doi.org/10.1080/10942910600580625.

2. Y.F. Sasaki, S. Kawaguchi, A. Kamaya, M. Ohshita, K. Kabasawa, K. Iwama, K. Taniguchi and S. Tsuda, Mutat. Res. Genet. Toxicol. Environ. Mutagen., 519, 103 (2002);

https://doi.org/10.1016/S1383-5718(02)00128-6.

3. K. Dastmalchi, H.J. Damien Dorman, P.P. Oinonen, Y. Darwis, I. Laakso and R. Hiltunen, LWT-Food Sci. Technol., 41, 391 (2008); https://doi.org/10.1016/j.lwt.2007.03.007.

4. M. Nadeem, F.M. Anjum, S. Hussian, M.I. Khan, M.R. Khan and S. Shahzad, Life Sci. Int. J., 4, 1349 (2010).

5. M.I. Dias, L. Barros, M.J. Sousa and I.C. Ferreira, Plant Foods Hum. Nutr., 66, 181 (2011); https://doi.org/10.1007/s11130-011-0227-3.

6. A.M. Gray and P.R. Flatt, Br. J. Nutr., 81, 203 (1999); https://doi.org/10.1017/S0007114599000392.

7. V. Chithra and S. Leelamma, Plant Foods Hum. Nutr., 51, 167 (1997); https://doi.org/10.1023/A:1007975430328.

8. S. Sabahat and T. Perween, Pak. J. Bot., 39, 913 (2007).

9. G.K. Jayaprakasha, B. Girennavar and B.S. Patil, LWT-Food Sci. Technol., 41, 376 (2008); https://doi.org/10.1016/j.1wt.2007.03.017.

10. K. Srinivasan, Int. J. Food Sci. Nutr., 56, 399 (2005); https://doi.org/10.1080/09637480500512872.

11. P. Dhanapakiam, J.M. Joseph, V.K. Ramaswamy, M. Moorthi and A.S. Kumar, J. Environ. Biol., 29, 53 (2008).

12. G. Aruna and V. Baskaran, Food Chem., 123, 404 (2010); https://doi.org/10.1016/j.foodchem.2010.04.056.

13. S.S. Jangra, V.K. Madan and S. Singh, J. Indian Chem. Soc., 92, 1149 (2015).

14. V.L. Singleton and J.A. Rossi, Am. J. Enol. Vitic., 16, 144 (1965).

15. D. Marinova, F. Ribarova and M. Atanassova, J. Univ. Chem. Technol. Metallurgy, 40, 255 (2005).

16. J.D. Hiscox and G.F. Israelstam, Can. J. Bot., 57, 1332 (1979); https://doi.org/10.1139/b79-163.

17. T. Hatano, H. Kagawa, T. Yasuhara and T. Okuda, Chem. Pharm. Bull. (Tokyo), 36, 2090 (1988); https://doi.org/10.1248/cpb.36.2090.

18. M.E. Hidalgo, E. Fernandez, W. Quilhot and E. Lissi, Phytochemistry, 37, 1585 (1994); https://doi.org/10.1016/S0031-9422(00)89571-0.

19. A. Luis, F. Domingues, C. Gill and A.P. Duarte, J. Med. Plants Res., 3, 886 (2009).

20. M.A. Al-Mamary, Malays. J. Nutr., 8, 179 (2002).

21. R. Oonsivilai, M.G. Ferruzzi and S. Ningsanond, Asian J. Food Ag-Ind., 1, 116 (2008). 
22. Y. Wang and B. Xu, J. Nutr. Food Sci., 2, 1009 (2014).

23. L. Ji, J. Wu, W. Gao, J. Wei, J. Yang and C. Guo, J. Food Sci., 76, C1257 (2011); https://doi.org/10.1111/j.1750-3841.2011.02402.x.

24. V. Kothari and S. Seshadri, Nutr. Food Sci., 40, 403 (2010); https://doi.org/10.1108/00346651011062050.

25. S.P. Tan, S.E. Parks, C.E. Stathopoulos and P.D. Roach, Food Nutr. Sci., 5, 458 (2014); https://doi.org/10.4236/fns.2014.55054.

26. J. Loaiza and M. Cantwell, HortScience, 32, 104 (1997).

27. G. Kofidis, A. Giannakoula and I.F. Ilias, Acta Biol. Cracov. Ser.; Bot., 50, 55 (2008).
28. T. Juntachote and E. Berghofer, Food Chem., 92, 193 (2005); https://doi.org/10.1016/j.foodchem.2004.04.044.

29. C. Parthiban, C. Saranya, K. Girija, A. Hemalatha, P. Anantharaman and M. Suresh, Int. J. Curr. Microbiol. Appl. Sci., 2, 64 (2013).

30. B. Lapornik, M. Prosek and A.G. Wondra, J. Food Eng., 71, 214 (2005); https://doi.org/10.1016/j.jfoodeng.2004.10.036.

31. M. Mazandarani, P.Z. Moghaddam, H. Baiat, M.R. Zolfaghari, E.A. Ghaemi and H. Hemati, Indian J. Plant. Physiol., 1, 169 (2011).

32. C. Kaur and H.C. Kapoor, Int. J. Food Sci. Technol., 37, 153 (2002); https://doi.org/10.1046/j.1365-2621.2002.00552.x.

33. A. Ismail and T.S. Hong, Malays. J. Nutr., 8, 167 (2002). 